\title{
Endoscopic sigmoidopexy with placement of a Chait catheter: a new procedure to prevent recurrent sigmoid volvulus?
}

An 80-year-old woman with a history of dementia and constipation was hospitalized three times within 3 years for recurrent episodes of sigmoid volvulus. As this patient was at high risk of surgical complications, a minimally invasive strategy (i.e. endoscopic sigmoidopexy), was decided after multidisciplinary discussion. In addition to previously described methods of endoscopic sigmoidopexy [1], we proposed to implant a Chait cecostomy catheter (Cook Medical, Bloomington, Indiana, USA) ( $>$ Video 1 ), as for patients treated by percutaneous endoscopic cecostomy for severe constipation $[2,3]$.

Under sedation and after enhanced bowel preparation and antibiotic prophylaxis, a colonoscopy was performed by the first operator. On reaching the sigmoid flexure, transillumination and abdominal wall finger test in sterile conditions were used by the second operator to define the optimal site for catheter placement. Local anesthesia using ropivacaine was performed with a subcutaneous needle and confirmed the feasibility of percutaneous access under endoscopic guidance. Three anchors were then placed to fix the sigmoid to the abdominal wall ( Fig.1). After making a small skin incision, a trocar needle was inserted in the center of the anchors and an $80-\mathrm{cm}$ guidewire was placed through the trocar, which was then removed. Over the guidewire, three dilators 6,8 , and $10 \mathrm{Fr}$ were introduced consecutively allowing subsequent placement of the Chait catheter ( $\triangleright$ Fig. 2).

The patient was discharged the following day and returned 2 weeks later to undergo colonic antegrade enema and thus check catheter permeability. No postoperative complications occurred and the catheter tolerance was good. At 1year follow-up, the patient had no recurrence of volvulus.

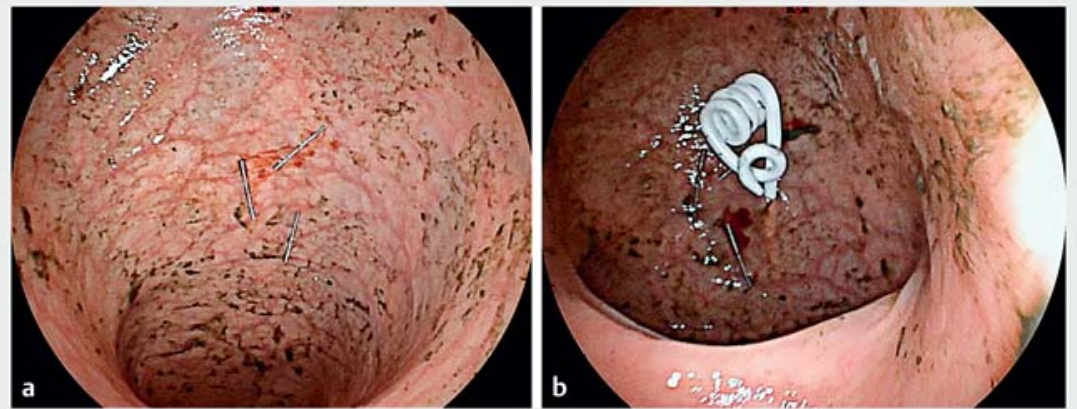

Fig. 1 Endoscopic view of the procedure. a Anchors. b Chait catheter.

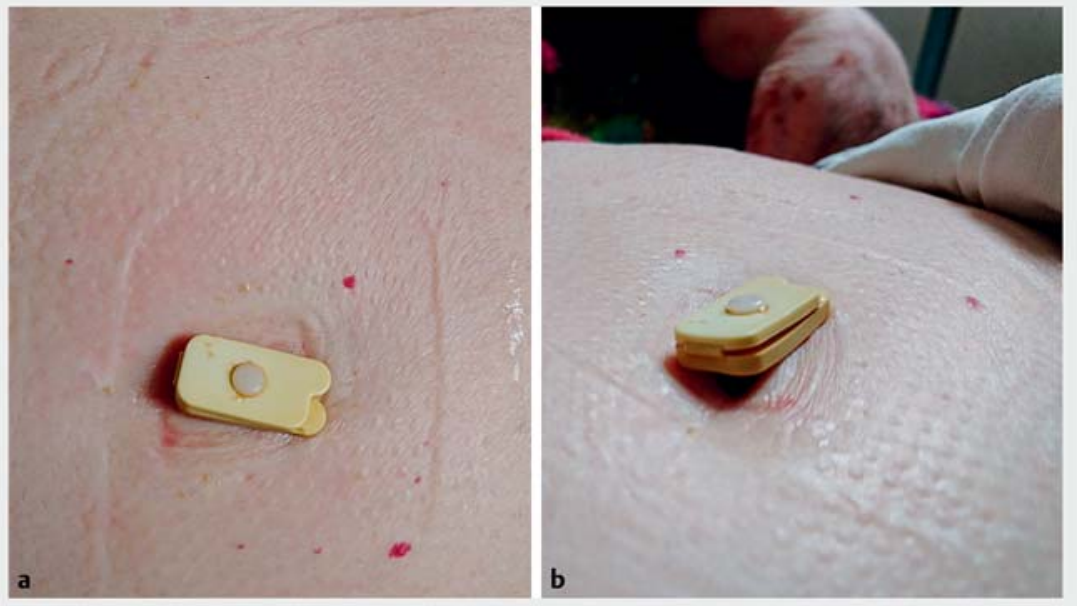

Fig. 2 The patient's abdomen at 1 year follow-up.

Endoscopic sigmoidopexy with placement of a Chait catheter could be a promising method to prevent recurrence of sigmoid volvulus in patients with contraindication to surgery, as it provides not only bowel fixation but also allows ondemand colonic enemas or decompression.

Endoscopy_UCTN_Code_TTT_1AQ_2A]

\section{Acknowledgment}

Funding provided by a FARE grant from the SNFGE.

Competing interests

None 


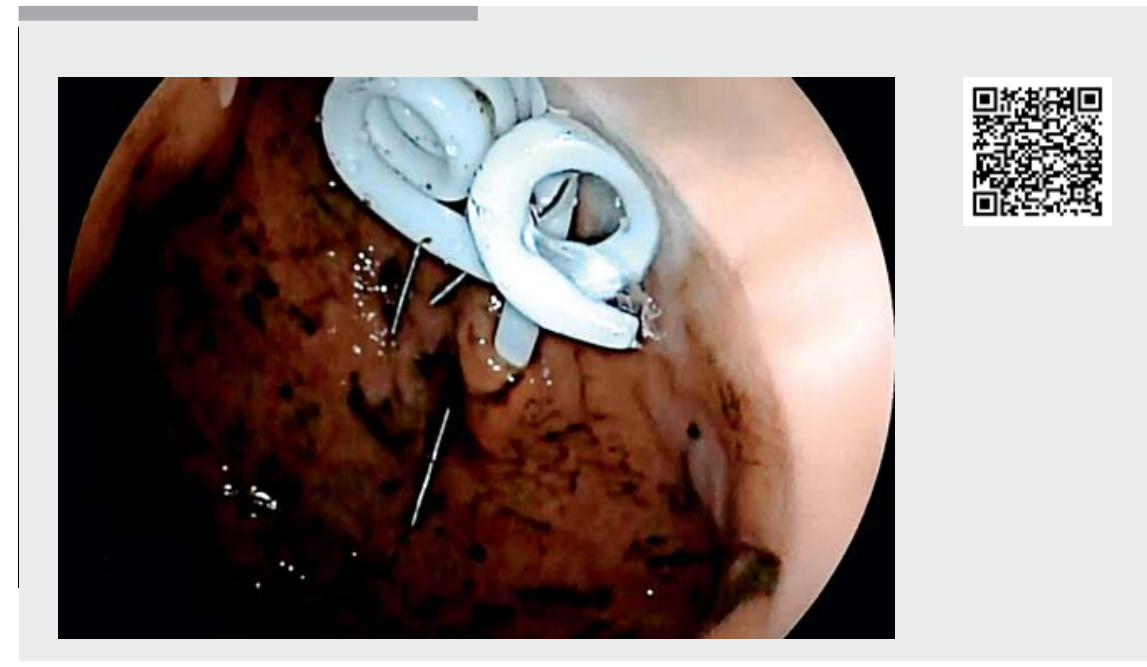

$\checkmark$ Video 1 Endoscopic sigmoidopexy with placement of a Chait catheter for recurrent sigmoid volvulus.

\section{The authors}

Lucille Quénéhervé', Pierrine Le Bras' ${ }^{1}$, Marianne Le Rhun ${ }^{2}$, Emmanuel Coron ${ }^{1}$

1 Institut des Maladies de l'Appareil Digestif (IMAD), University Hospital of Nantes, Nantes, France

2 Pôle de Gérontologie Clinique, University Hospital of Nantes, Nantes, France

\section{Corresponding author}

\section{Lucille Quénéhervé, MD}

University Hospital of Nantes, Institut des Maladies de l'Appareil digestif, IMAD, Place Alexis Ricordeau, Nantes, 44000, France Fax: +33-2-40083154

lucille.queneherve@chu-nantes.fr

\section{Bibliography}

DOI https://doi.org/10.1055/a-1022-4358

Published online: 6.12.2019

Endoscopy 2020; 52: 409-410

(c) Georg Thieme Verlag KG

Stuttgart · New York

ISSN 0013-726X

\section{ENDOSCOPY E-VIDEOS \\ https://eref.thieme.de/e-videos}

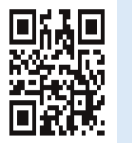

Endoscopy E-Videos is a free access online section, reporting on interesting cases and new techniques in gastroenterological endoscopy. All papers include a high quality video and all contributions are freely accessible online.

This section has its own submission website at https://mc.manuscriptcentral.com/e-videos
[1] Frank L, Moran A, Beaton C. Use of percutaneous endoscopic colostomy (PEC) to treat sigmoid volvulus: a systematic review. Endosc Int Open 2016; 4: E737-741

[2] Duchalais E, Meurette G, Mantoo SK et al. Percutaneous endoscopic caecostomy for severe constipation in adults: feasibility, durability, functional and quality of life results at 1 year follow-up. Surg Endosc 2015; 29: 620-626

[3] Rivera MT, Kugathasan S, Berger W et al. Percutaneous colonoscopic cecostomy for management of chronic constipation in children. Gastrointest Endosc 2001; 53: 225-228 